\title{
50TH $\mid$ Neuroradiology Back to the Future: Head and ANNIVERSARY Neck Imaging
}

E.G. Hoeffner

S.K. Mukherji

A. Srinivasan

D.J. Quint

\begin{abstract}
SUMMARY: Imaging of the head and neck was initially described within the first year after Roentgen's discovery of the $x$-ray and was used to localize foreign bodies in the head and neck area, including the orbital, laryngeal, and esophageal regions. Subsequently, $x$-rays were used to evaluate the air-filled paranasal sinuses, the pneumatized temporal bone, and the upper aerodigestive tract. Special views for evaluating these structures were developed by early investigators. As contrast agents were developed, a variety of invasive procedures were developed to assess the structures of the head and neck. CT and MR imaging were applied to the extracranial head and neck slightly later than the brain and spine; these modalities revolutionized head and neck radiology, finally allowing assessment of the deeper structures of this complex anatomic region.
\end{abstract}

maging of the head and neck region began shortly after the discovery of x-rays. With time, radiographic technique advanced, and various radiographic procedures related to the head and neck region were introduced. Until the advent of CT and MR imaging, the radiologist could only detect disease in the head and neck region if it altered or destroyed bone or impinged on a normally air-filled structure. Cross-sectional imaging finally allowed the noninvasive visualization of the deeper structures of the complex head and neck region and altered how patients with diseases affecting this region are diagnosed and treated.

\section{The Beginning: X-rays of the Head and Neck}

Reports of the first clinically useful x-rays of the head and neck region appeared within months of Roentgen's discovery in late 1895 , with $\mathrm{x}$-rays performed to locate foreign bodies, including those lodged in the proximal esophagus and orbit. ${ }^{1-5}$ The first report of x-rays of the larynx was published by Dr John MacIntyre of Great Britain in 1896. ${ }^{1,3,6}$ The first radiologic description of a laryngeal tumor appeared in the medical literature in $1901 .^{7}$ As early as 1896 , MacIntyre opined that fluoroscopy would likely be more useful in assessing the larynx than radiographs. Movement of the larynx and swallowing function under fluoroscopy was described in the early 1900s by Max Scheier, a German otolaryngologist, who also studied the radiologic appearance of calcified laryngeal cartilage. ${ }^{7}$ Other early investigators stressed the importance of the lateral (as opposed to frontal) laryngeal x-ray, which was not hampered by the overlapping bones of the cervical spine. ${ }^{7}$ In 1928 , Preston Hickey described the appearance of the normal larynx by using the lateral view and low-kilovoltage technique, which emphasized the soft tissues. ${ }^{7,8}$ Numerous diseases of the larynx and their radiographic appearance were described in the medical literature during the first quarter of the 20th century, including tumors; infections, in particular tuberculosis and syphilis; and strictures from a variety of causes. ${ }^{7}$

From the Division of Neuroradiology, Department of Radiology, University of Michigan Health System, Ann Arbor, Michigan

Please address correspondence to Ellen G. Hoeffner, MD, Division of Neuroradiology, Department of Radiology, University of Michigan Health System, 1500 East Medical Center Dr, UH B2A 209G, Ann Arbor, Ml 48109; e-mail: hoeffner@umich.edu

Indicates open access to non-subscribers at www.ajnr.org

http://dx.doi.org/10.3174/ajnr.A3365
In 1896 , Scheier was also one of the first physicians to realize the value of $\mathrm{x}$-rays of the paranasal sinuses in patients with sinus disease. This evolved from a clinical need to define the sinuses before surgery and, in some cases, avoid unnecessary operations. ${ }^{1,3}$ Additional reports of sinus $\mathrm{x}$-rays soon followed from investigators in Europe and the United States. Many of these early investigations described special $\mathrm{x}$-ray views that allowed the best visualization of the various paranasal sinuses despite the overlapping bones of the skull and maxillofacial region. ${ }^{1,3}$ These views included the Caldwell view, described by Eugene W. Caldwell, MD, in 1907 and the Waters view, introduced 8 years later by Drs C.A. Waters and C.W. Waldron. ${ }^{9,10}$ Many of these views also optimized radiographic delineation of the bones of the maxillofacial region and bony orbit, with additional views developed with time to assess specific areas, such as the optic canal (Fig 1). ${ }^{11}$ Other innovations included immobilizing the patient while obtaining the $\mathrm{x}$-ray, with a chair developed for this purpose in 1915 that combined a head frame and cassette holder, and erect films to demonstrate fluid levels in the paranasal sinuses, both described by Dr Percy Brown in $1915 .{ }^{12,13}$ The ability to identify the sphenoid sinuses on $\mathrm{x}$-rays led to the introduction of the transsphenoidal approach to pituitary tumors in 1909, which, in many cases, replaced the intracranial approach, which was associated with high morbidity. This approach was suggested by Dr Arthur Schüller of Austria, considered by many to be the father of neuroradiology. ${ }^{1,3,14}$ As with all $\mathrm{x}$-ray examinations in the late 1800 s and early 1900 s, exposure times were long, lasting minutes. In fact, hair loss was common following sinus x-rays. ${ }^{3}$

The initial effort at temporal bone x-rays in the early 1900 s was primarily an attempt to diagnose causes of hearing loss, particularly infections and cholesteatoma of the middle ear and the mastoid air cells. ${ }^{3,15}$ Due to the complex anatomy of the temporal bone, special views had to be developed to depict the various portions of the temporal bone, particularly the middle ear and mastoid air cells. ${ }^{3}$ Many of these views were lateral projections with varying degrees of angulation. These special views of the temporal bones included the Schüller, Mayer, Stenver, and Towne views (Fig 2). ${ }^{1,3,16}$ Another early investigator, Swedish pathologist Folke Henschen, in conjunction with radiologist Gösta Forssell, hypothesized as early as 1910 that acoustic tumors should produce widening of the internal acoustic meatus as they had seen at autopsy. 


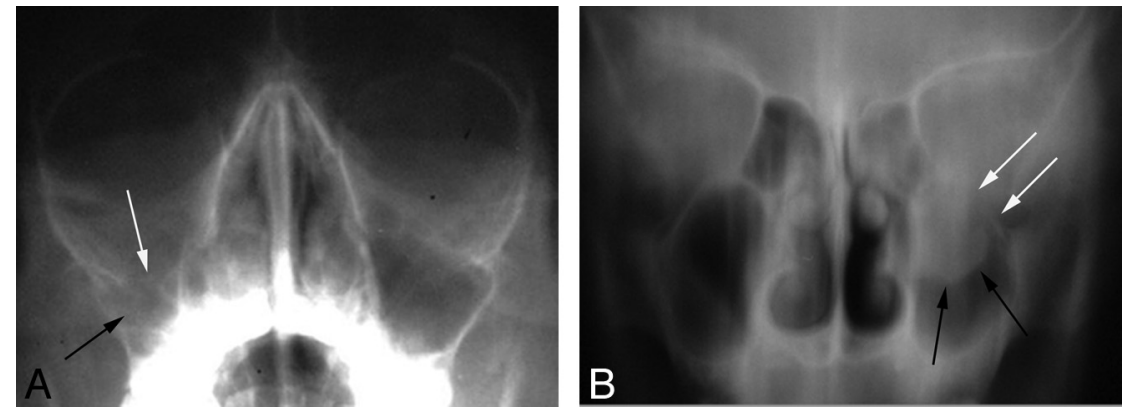

Fig 1. A, Waters view of the paranasal sinuses with a depressed right orbital floor fracture (white arrow) and an opacified right maxillary sinus (black arrow). $B$, Coronal tomogram in a different patient shows a left orbital floor fracture (white arrows) with partial left maxillary sinus opacification (black arrows).

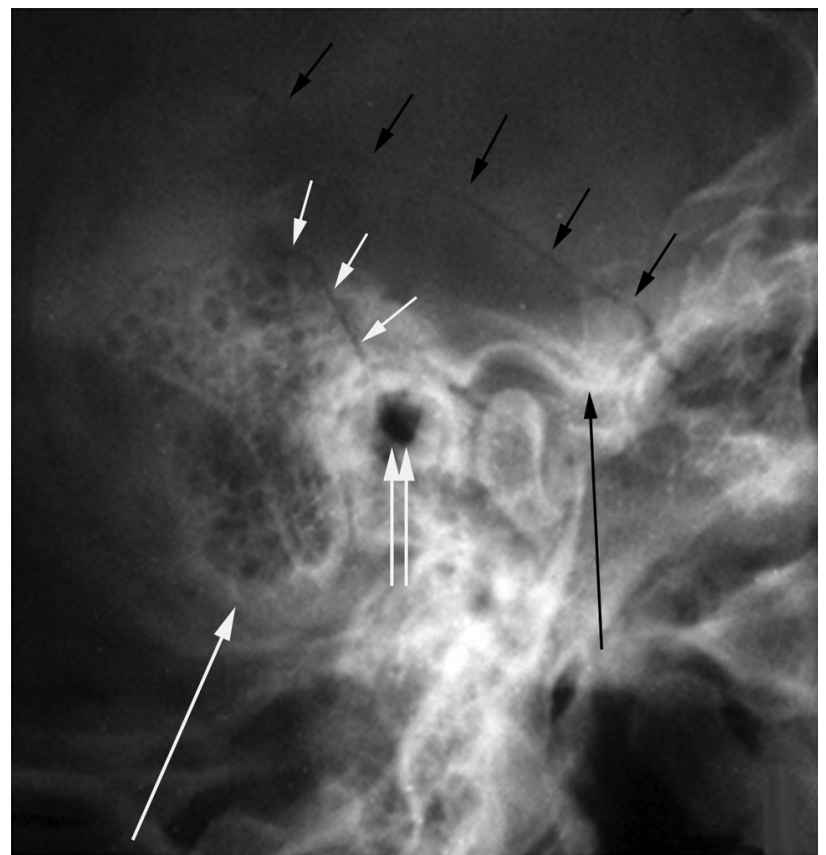

Fig 2. Schüller view of the temporal bone showing a fracture (short white arrows) extending through the squamosal temporal bone, anterior to the mastoid process (long white arrow) and into the external auditory canal (double white arrows). A second fracture (short black arrows) extends through the parietal bone, into the squamosal temporal bone, and then into the skull base just anterior to the articular eminence (large black arrow) of the temporal bone.

Two years later they were able to prove this hypothesis radiographically. ${ }^{17}$

The first $\mathrm{x}$-ray atlas of laryngeal disease was published by Dr Arthur Thost in Germany in 1913. The following year the book The Roentgen Diagnosis for the ENT Physician was published in Germany. In 1930, one of the earliest books on otologic radiology was published in Austria. ${ }^{3}$

\section{Contrast Examinations of the Head and Neck}

Despite the previously mentioned advances, diseases of the head and neck could only be diagnosed radiographically if they opacified normal air-containing structures or destroyed or otherwise altered the bone. ${ }^{18}$

A dacryocystogram was the first contrast study of the head and neck region, performed by Dr A.E. Ewing ${ }^{19}$ in 1906, using bismuth subnitrate in liquid petroleum as the contrast agent. In 1922, Sicard and his student Forestier ${ }^{20}$ reported on the intrathecal use of iodized poppy seed oil, Lipiodol (Andre

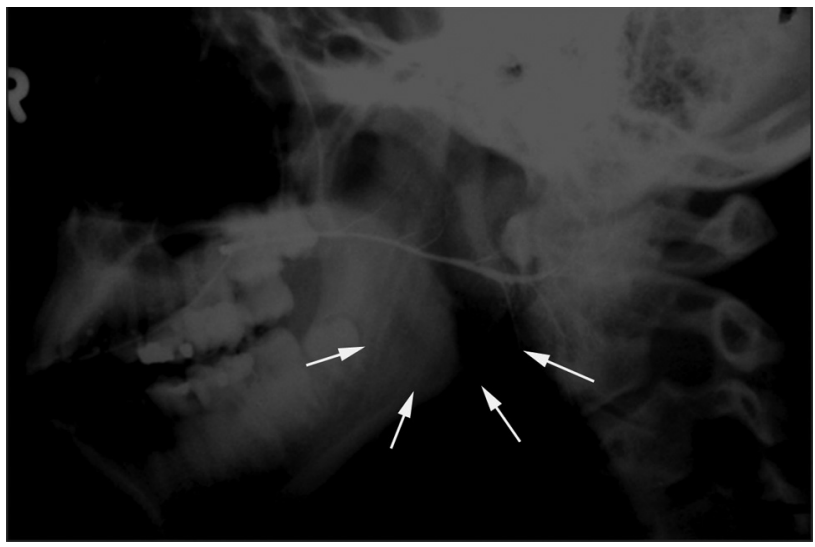

Fig 3. A 20-year-old man with a lump near the angle of the mandible. Oblique view from a parotid sialogram shows distortion of secondary ducts and a "ductless" appearance (arrows) near the angle of the mandible, related to a pleomorphic adenoma of the parotid gland.

Guerbet, Aulnay-sous-Bois, France), in diagnosing spinal masses. The first dacryocystogram using Lipiodol was reported in $1924 .^{21}$ Subsequently, other oil-based contrast agents were used for dacryocystography, including ethiodized oil (Ethiodol) and iophendylate (Pantopaque; Lafayette Pharmacal, Lafayette, Indiana). ${ }^{21,22}$ Oil-based contrast agents continued to be used for decades for dacryocystography though there were some disadvantages. Specifically, the oil-based compounds were not completely miscible, with tears resulting in globules of contrast and failure to fill the entire nasolacrimal system. ${ }^{21-23}$ Extravasated contrast could remain in the soft tissues for years and incite granuloma formation. Because the oil-based agents were more viscous than tears, they at times needed to be heated before injecting. ${ }^{22,23}$ Following their development, numerous water-soluble contrast agents were used for dacryocystography. Some of these agents, particularly the ionic agents, were too irritating to inject in the lacrimal system. Because of their lower viscosity, the water-soluble agents often drained so rapidly from the lacrimal system that higher injection rates and volumes were required. ${ }^{23}$

The first known sialography was performed in France in 1913. A bismuth solution was injected into the submandibular duct, demonstrating a stone; however, the use of bismuth as a contrast agent was soon discontinued due to cases of bismuth poisoning. ${ }^{1,3}$ A $20 \%$ solution of potassium iodide in water was also used for sialography in the 1920s but was abandoned because it was too irritating. ${ }^{24}$ In 1931, Lipiodol was first introduced for sialography. This material or similar-type contrast 

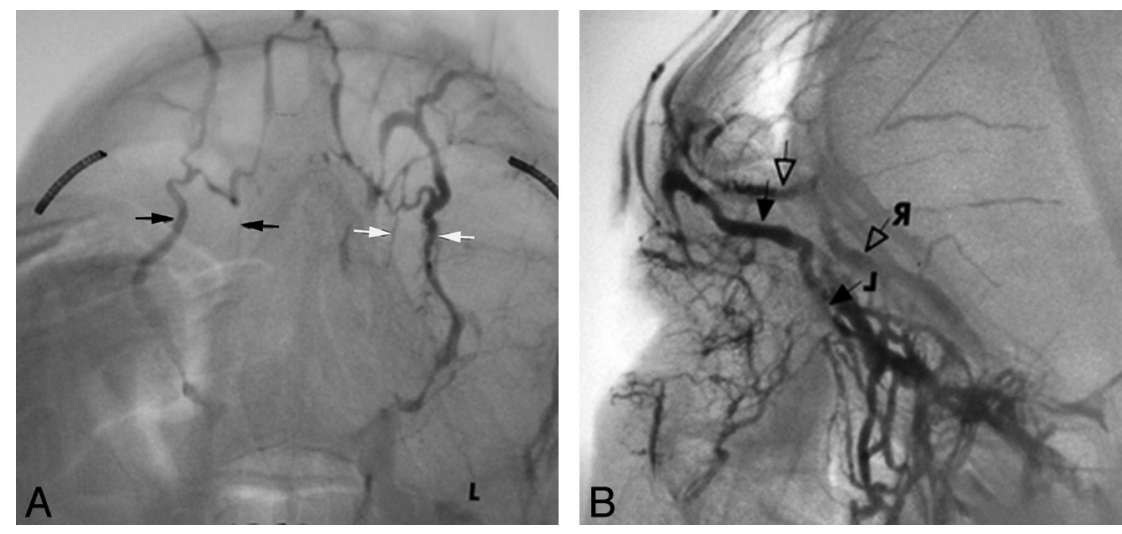

Fig 4. A 59-year-old man with left proptosis and negative findings on orbital x-rays and tomograms. Orbital venography was performed following percutaneous puncture of a lateral frontal vein. Frontal view from an orbital venogram $(A)$ shows medial displacement of the anterior and midportions of the left superior ophthalmic vein (SOV) (white arrows) compared with the right (black arrows). Lateral view from an orbital venogram $(B)$ demonstrates inferior displacement of the left SOV (open arrows) compared with the right (solid arrows). Imaging findings are suggestive of a tumor in the anterior and midportion of the orbit laterally. Biopsy of mass revealed lacrimal gland carcinoma.

agents continued to be used for decades, though other agents including Pantopaque and water-soluble contrast agents were also used. ${ }^{24}$ Sialography was used for both benign and malignant disease of the salivary glands. This was often a painful procedure for patients, and contrast leakage into the mouth could cause consternation for the radiologist (Fig 3). ${ }^{25}$

Lipiodol was also used for laryngography and contrast studies of the paranasal sinuses. The first use of Lipiodol in the larynx and pharynx was by Dr Samuel Iglauer ${ }^{26}$ in 1926; however, the Lipiodol often resulted in irregular coating of the larynx. ${ }^{3,7}$ In 1942, laryngography by using a pump atomizer that sprayed a $40 \%$ solution of neoiodipin through a curved cannula extending behind the epiglottis was described by Farinas. ${ }^{27}$ This technique provided excellent images but required the larynx to be anesthetized and cannulated. Occasionally this procedure resulted in laryngeal spasm., ${ }^{3,27}$ Laryngography was further advanced by Powers et al, ${ }^{28}$ who used propyliodone (Dionosil Oily; GlaxoSmithKline, Brentford, UK) as the contrast agent following topical anesthesia of the pharynx and larynx. In 1970, the use of powdered tantalum as a contrast agent for laryngography was described by Zamel et al. ${ }^{29}$ The advantages of powdered tantalum included the ability to perform the examination without topical anesthesia, because the tantalum could be inhaled via the mouth; improved radiopacity compared with iodine; and better adherence to the mucosa even with coughing and swallowing. ${ }^{29}$ The main indication for laryngography was cancer of the larynx, though laryngeal and pharyngeal function and elasticity could also be evaluated when combined with fluoroscopy., Laryngograms still provided only information about the mucosal surface, with no information about deeper extension by a pathologic process. ${ }^{30}$

The injection of iodized oil into the paranasal sinuses was first described in 1926. With time, various methods were developed for the injection of contrast into the sinuses, including direct injection into a sinus; completely filling it; and an indirect method, sometimes referred to as "suffusion." In the latter technique, contrast was injected into the nasal fossa and manipulated into the sinuses by gravity during pressure changes in the nose, either self-induced by the patient or with suction applied to the nose. ${ }^{31,32}$ Delayed films were sometimes obtained 48-96 hours after the contrast injection in an effort to obtain physiologic or functional information about the emptying ability of the sinuses. ${ }^{32}$

Orbital venography was first described in 1951, with this imaging technique initially requiring surgical exposure of the angular vein. In the following decade, percutaneous and transjugular access to the pertinent vasculature was developed. ${ }^{33-36}$ By assessing the orbital veins for narrowing, occlusion, displacement, and other intrinsic abnormalities, this technique was used to diagnose a variety of benign and malignant processes of the orbits and cavernous sinuses. ${ }^{33}$ Although this technique was relatively well-tolerated by patients with only minimal sedation usually required, transient or permanent vision loss did sometimes occur as a complication of the procedure (Fig 4$).^{36}$

As with imaging of other portions of the central nervous system, injected air was used as a contrast agent in orbital imaging. Both sub-Tenon and retrobulbar injections of air were used to localize foreign bodies and diagnose orbital masses. ${ }^{11,37,38}$ A variety of oil-based and water-soluble contrast agents was also injected into the retrobulbar space..$^{11,39,40}$ The oily contrast media tended to pool in the tissue, making interpretation difficult. It was reabsorbed slowly and, in the long term, was often an irritant. The water-soluble agents were so rapidly absorbed that it made imaging difficult. Regardless of contrast agent used, it was not always possible to visualize small masses, and no information was provided about the blood supply to a lesion. ${ }^{11}$

Angiography was occasionally used to diagnose pathologic processes of the orbits, paranasal sinuses, nose, temporal bone, and neck regions, including paragangliomas, juvenile nasal angiofibromas, and acoustic neuromas. ${ }^{11,12,15}$ Egas Moniz $^{41}$ obtained the first internal carotid artery angiogram via cut-down of the carotid artery in 1927. Seldinger described using catheters placed percutaneously as a replacement for direct needle punctures in 1953. Lindgren described transfemoral catheterization of the vertebral artery in 1954. However, routine transfemoral catheterization of the intracranial vessels did not become common until the mid-1960s. ${ }^{41-43}$ This finally allowed visualization of all the extra- and intracranial cerebral arteries via a single femoral arterial puncture. ${ }^{43} \mathrm{Tu}-$ mors of the head and neck region were primarily diagnosed by 

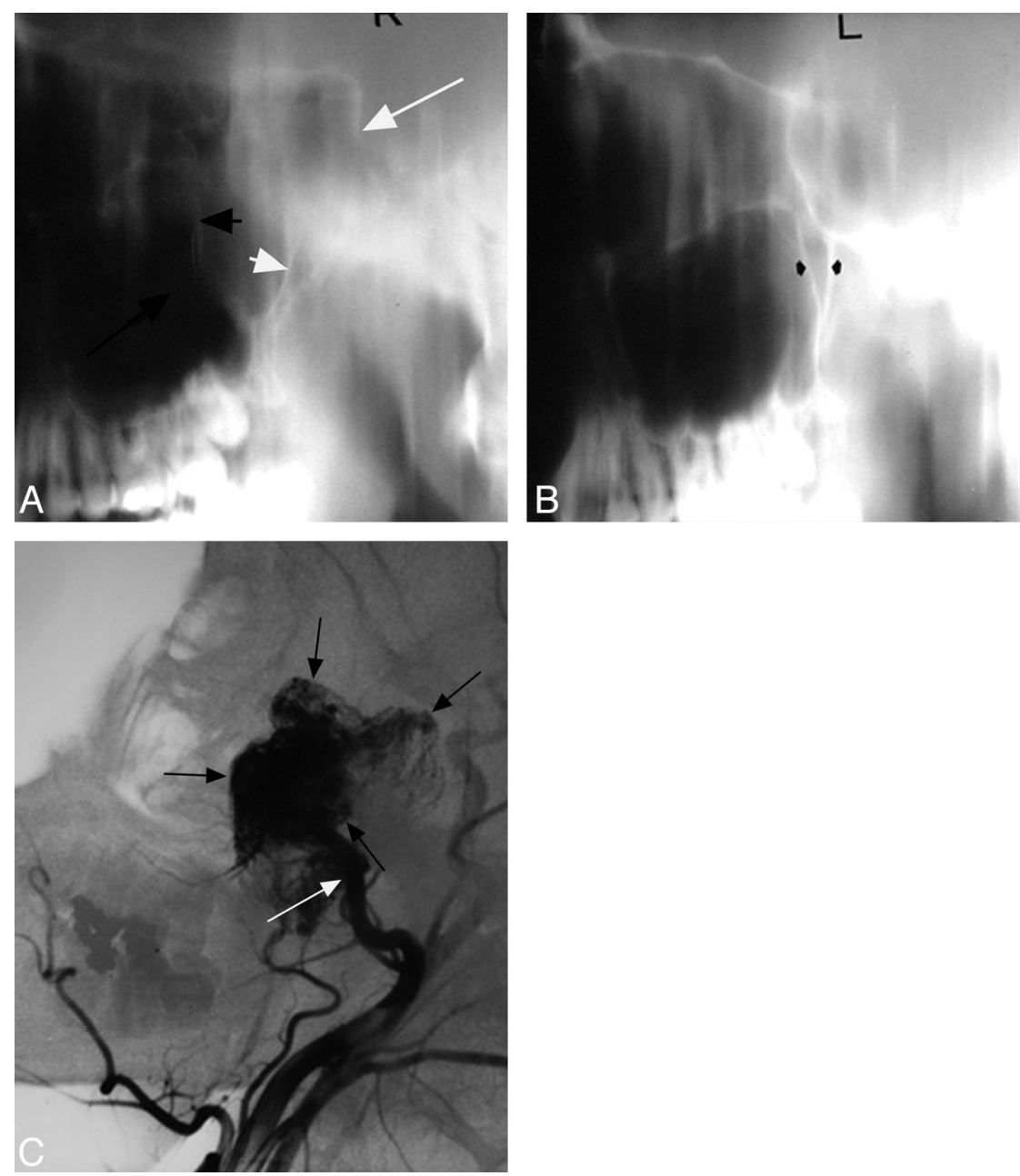

Fig 5. Adolescent boy with epistaxis. Lateral tomogram through the right side of the nasopharynx $(A)$ shows a nasopharyngeal mass extending into and enlarging the pterygopalatine fossa with forward bowing of the posterior wall of the maxillary antrum (short black arrow) and posterior displacement of the pterygoid process (short white arrow). The mass also extends into the anterior half of the sphenoid sinus (long white arrow) and right maxillary antrum (long black arrow). B, Lateral tomogram through the left side of the nasopharynx shows a normal pterygopalatine fossa (arrows). C, Lateral view from the right external carotid artery angiogram shows a very vascular mass (black arrows) in the nasopharynx, right pterygopalatine fossa, anterior sphenoid sinus, posterior right maxillary sinus, and posterior inferior right orbit. Supply is from the internal maxillary artery (white arrow).

their pattern of displacement of normal vessels and tumor vascularity (Fig 5). ${ }^{12,15}$

\section{The Development of Tomography and the Evolution of Conventional Radiography}

Tomography was introduced in the early 1930s with most crediting Bernard Ziedses Des Plantes of the Netherlands with first describing this technique in $1931 .{ }^{3,44}$ Although originally known by a variety of terms, including planigraphy, stratigraphy, laminagraphy, and sectional radiography, the technique was based on linear movements in opposite directions of the $\mathrm{x}$ ray tube and the film-containing cassette holder. Selective tissue planes could be seen in detail with exclusion of anatomic structures that were located above and below the plane of interest. With time, modifications in tube movement were introduced to improve anatomic detail, including circular, elliptic, and hypocycloidal tomography. It eventually became possible to obtain images with a section thickness as small as $1 \mathrm{~mm} .^{3}$ The first publication on tomography of the larynx appeared in 1936 and stressed the value of tomography in diagnosing laryngeal cancer. ${ }^{7}$ During the next 5 years, multiple additional studies were published on laryngeal tomogra- phy illustrating the normal larynx as well as a variety of benign and malignant laryngeal pathologic processes. ${ }^{7,45}$ Compared with laryngography, tomography had the advantage of being convenient and required no patient preparation. ${ }^{7,46}$

In the late 1930s and early 1940s, tomography of the paranasal sinuses and temporal bones was introduced; however, it was the development of complex motion tomography (eg, hypocycloidal) in the 1950s that really advanced the imaging of the paranasal sinuses, orbits, facial bones, temporal bones, and skull base. ${ }^{3,12,15,47}$ In particular, Galdino Valvassori at the University of Chicago was instrumental in developing the role of complex motion tomography of the temporal bone in the early 1960s. It was Valvassori's course on radiology in otolaryngology and ophthalmology that evolved into the founding of the American Society of Head and Neck Radiology in 1976. ${ }^{48}$ Tomography was often combined with some of the various contrast studies of the head and neck region described above and was often used in conjunction with conventional $\mathrm{x}$-rays as a screening tool, particularly for assessment of the larynx and temporal bones. ${ }^{49,50}$ Limitations of tomography included being time consuming and therefore expensive to 
perform. There were also concerns about the relatively high radiation dose to the patient. ${ }^{50}$

Conventional radiography remained a mainstay in head and neck imaging with advances made with time in the imaging of this region. Radiographic technique was varied to accentuate different structures, as seen in the following examples. A high-kilovoltage selective filtration technique was developed for radiography of the larynx in an effort to minimize confusion from the overlapping shadows of the cervical spine. ${ }^{7,51}$ Fluoroscopic and spot-film examination of the larynx was also performed, particularly to assess the vocal cords and subglottic region. This examination could be performed quickly on equipment available in most radiology departments without the use of a contrast agent and no need for anesthesia or other patient preparation. ${ }^{52,53}$ The use of xeroradiography of the larynx was also advocated to improve delineation of the larynx and surrounding soft tissues. ${ }^{54}$ Multiple radiographic views were developed to fully assess the detailed overlapping anatomy of the head and neck. A 1938 article by Shebesta $^{55}$ indicated that at least 24 projections for imaging the temporal bone had been described by that time, which sometimes led to confusion among radiologists as to which views should be obtained.

\section{Cross-Sectional Imaging of the Head and Neck}

As with imaging of the brain and spine, the advent of CT and MR imaging a short time later revolutionized the field of radiology. ${ }^{14,56}$ The first CT scanner introduced in 1973 by Electric and Musical Industries (London, UK) was designed to image only the head, but by the following year, an article had already been published describing a modification of the usual head scanning technique that afforded the first rudimentary CT images of the orbit. ${ }^{57-59}$ The first whole-body CT scanner was introduced in $1974 .{ }^{60}$ The larger gantry aperture and the ability to angle the gantry allowed some degree of direct coronal CT images to be obtained. Coronal imaging was soon applied to the orbit, paranasal sinuses, maxillofacial bones, and temporal bone. ${ }^{61,62}$ During the next several years, multiple studies were published describing the CT findings of a variety of infectious, inflammatory, traumatic, and neoplastic diseases of the head and neck. ${ }^{63-65}$ Although at this time, the fine bone detail and destructive osseous processes were still better assessed with conventional tomography, soft-tissue extent of disease was clearly better delineated with CT. ${ }^{63,64}$ The use of iodinated contrast material further improved the conspicuity of many abnormalities. ${ }^{3}$

By the mid-1980s, studies had shown the utility of CT for staging head and neck tumors as an improvement in comparison with the clinical examination and routine radiographic modalities in many patients. CT could detect lymph node metastases that were clinically occult and extranodal extension. ${ }^{48,66,67}$ CT-guided biopsy of head and neck processes was also introduced, which allowed the less invasive (versus surgery) confirmation of the presence and extent of primary and metastatic disease. ${ }^{68}$ These advances led to greater precision in treatment planning and decreased morbidity and mortality. ${ }^{3}$ With the introduction of functional endoscopic sinus surgery in the early 1990s, coronal sinus CT became an important imaging technique before surgery and also aided in the development of this surgical technique. ${ }^{3,48,69}$ More recently, the introduction of helical CT and multidetector row CT has led to shorter examination times, fewer motion artifacts, and greater spatial resolution, making multiplanar reformatted images and CT angiography clinically feasible. ${ }^{70-73}$ These advances in CT technique also permitted less contrast to be used while still obtaining excellent contrast opacification compared with conventional CT. ${ }^{72}$ Functional CT now plays an important role in head and neck imaging, particularly with regard to head and neck malignancies, with PET and perfusion CT. ${ }^{74,75}$

The first commercial MR imaging scanner was introduced in 1980, and the first superconducting magnet was put in clinical use in 1981; however, MR imaging studies of the extracranial head and neck were more slowly accepted than those of the brain and spine. ${ }^{76,77}$ The delayed development in MR imaging was related to technical difficulties in imaging the head and neck, including image quality, surface coils, motion artifacts, and anatomic variations that were not present in the brain and spine. The introduction of specialized surface coils in the mid 1980s for imaging of the head and neck region was the major technical advance that made MR imaging of this region clinically feasible. By the late 1980s, diagnostic MR imaging evaluation for a wide variety of head and neck lesions was possible. ${ }^{77}$ The soft-tissue resolution of MR imaging is significantly better in comparison with CT. In many cases, tumor margins were better delineated compared with CT, and subtle bone and cartilage invasion could be detected. ${ }^{77,78}$ The introduction of gadolinium-based contrast agents and fat-saturated images further improved the sensitivity of MR imaging for a variety of head and neck lesions. ${ }^{79,80}$ It was now possible to see enhancement of the cranial nerves in a variety of infectious, inflammatory, and neoplastic processes. ${ }^{48,81,82}$ The introduction of MR angiography further improved the diagnostic capability of MR imaging, particularly with regard to entities such as pulsatile tinnitus. ${ }^{83}$ The more recent clinical introduction of higher field strength (3T) MR imaging machines has led to improvements in signal and contrast resolution. ${ }^{84}$ Functional imaging has been used in the head and neck, though its application is not as robust as in the brain. Diffusion-weighted imaging has shown promise in distinguishing benign from malignant lesions and in assessing therapeutic responses in patients with head and neck cancer. ${ }^{85,86}$ As with CT perfusion, MR perfusion may be helpful in predicting tumor response to chemoradiation in patients with head and neck cancer. ${ }^{87,88}$

CT and MR imaging now both have wide, often complementary applications for the evaluation of head and neck processes. CT is usually the examination of choice for trauma, infections, bone erosion, conductive hearing loss, middle ear cholesteatoma, and sialoliths. MR imaging is superior at detecting perineural tumor spread, complicated infections, and disease processes with suspected intracranial and/or intraorbital extension. Both modalities now play a role in the imaging evaluation of head and neck masses and lymph nodes. ${ }^{89,90}$

\section{Conclusions}

As with imaging of the brain and spine, profound advances have been made in head and neck imaging that have had a positive impact on the diagnosis and treatment of patients. Until the emergence of CT and MR imaging, radiologists were mainly limited to diagnosing disease after it opacified a nor- 
mally air-filled structure or destroyed bone. A variety of invasive procedures added little to the radiologic armamentarium at that time. The currently available cross-sectional imaging techniques allow accurate depiction of the complex anatomy and pathologic processes of the head and neck regions that was likely undreamed of in the early days of radiology and have advanced the diagnosis and treatment of patients. We expect that progress will continue in the future, which will lead to even less invasive, safer, faster, more specific diagnostic techniques, resulting in even earlier diagnosis and treatment with a continuing positive impact on patient outcome.

Disclosures: Suresh Mukherji-UNRELATED: Consultancy. Phillips Healthcare, Comments: MRI consultant.

\section{References}

1. Chavda SV, Pahor AL. A century of ENT radiology. I Laryngol Otol 1996;110:5-9

2. Noyek AM. The history of otolaryngology/head and neck imaging in North America. Laryngoscope 1997;107:298-300

3. Weber AL. History of head and neck radiology: past, present and future. $R a$ diology 2001;218:15-24

4. Johnston F, Holland CT. Two cases of a halfpenny in the esophagus. BMJ 1896;2:1677

5. Raw N. Foreign body in the esophagus: localization by $\mathrm{X}$ rays: successful removal. $B M J$ 1896;2:1678

6. MacIntyre J. Roentgen rays in laryngeal surgery. BMJ 1896;1:1094

7. Noyek AM, Zizmor J. The evolution of diagnostic radiology of the larynx. J Otolaryngol 1977;6(supp 3):12-16

8. Hickey PM. Radiography of normal larynx. Radiology 1928;11:409-11

9. Caldwell EW. Skiagraphy of the accessory sinuses of the nose. AJR Am J Roentgenol 1907;1:27-30

10. Waters CA, Waldron CW. Roentgenology of accessory nasal sinuses describing modification of occipito-frontal position. AJR Am J Roentgenol 1915;2:633-39

11. Taveras JL, Hail BG. Radiography of the eye and orbit: a historical review. Surv Ophthalmol 1988;32:361-68

12. Noyek AM, Zizmor J. The evolution of diagnostic radiology of the paranasal sinuses. J Otolaryngol Suppl 1977;3:7-11

13. Brown $P$. The desirability of complete immobilization in roentgenizations of the head. AJR Am J Roentgenol 1915;11:680-83

14. Hoeffner EG, Mukherji SK, Srinivasan A, et al. Neuroradiology back to the future: brain imaging. AJNR Am J Neuroradiol 2012;33:5-11

15. Noyek AM, Zizmor J. The evolution of diagnostic radiology of the temporal bone. J Otolaryngol Suppl 1977;3:1-6

16. Schindler E. Arthur Schuller: pioneer of neuroradiology. AJNR Am J Neuroradiol 1997;18:1297-302

17. Bull JW. The history of neuroradiology. Proc Roy Soc Med 1970;63:637-43

18. Mayer EG. The technic of the roentgenologic examination of the temporal bone. Radiology 1926;7:306-17

19. Ewing AE. Roentgen ray demonstration of the lacrimal abscess cavity. Am J Ophthalmol 1909;26:1-4

20. Sicard JA, Forestier JE. Methode generale d'exploration radiologique par l'huile iodée (Lipiodol). Bull Soc Med Hop Paris 1922;46:463-68

21. Malik SRK, Gupta AK, Chaterjee S, et al. Dacryocystography of normal and pathological lacrimal systems. Br J Ophthal 1969;53:174-79

22. Schatz CJ. Dacryocystography. In: Bergerin RT, Osborn AG, Som PM, eds. Head and Neck Imaging Excluding the Brain. St Louis: Mosby; 1984:669-80

23. Munk PL, Burhenne LW, Buffam FV, et al. Dacryocystography: comparison of water-soluble and oil-based contrast agents. Radiology 1989;173:827-30

24. Osmer JC, Pleasants JE. Distension sialography. Radiology 1966;87:116-18

25. Holt JF. Sialography. Radiology 1957;68:584-85

26. Iglauer $S$. Use of injected iodized oil: roentgen diagnosis of laryngeal, tracheal and bronchopulmonary conditions. JAMA 1926;86:1874-84

27. Farinas PL. Muscography of the respiratory tract. Radiology 1942;39:84-87

28. Powers WE, McGee HH, Seaman WB. Contrast examination of the larynx and pharynx. Radiology 1957;68:169-78

29. Zamel N, Austin JH, Graf PD, et al. Powdered tantalum as a medium for human laryngography. Radiology 1970;94:547-53

30. Mancuso AA, Hanafee WH. A comparative evaluation of computed tomography and laryngography. Radiology 1979;133:131-38

31. Fraser RH. Diagnostic uses of Lipiodol in the paranasal sinuses. Radiology $1929 ; 6-26$

32. Schillinger R. An opaque survey of the nasal sinuses. Radiology 1940;35:1-16

33. Russell DB, Miller JD. Orbital venography. Radiology 1972;103:267-73
34. Dejean C, Boudet C. Du diagnostic des varices de l'orbite et leurs complications par la phlébographie. Bull Mém Soc Franc Ophtal 1951;64:374-77

35. Lombardi G, Passerini A. Venography of the orbit: technique and anatomy. Br J Radiology 1968;41:282-86

36. Safer JN, Guibor P. Ocular complications of orbital venography. Radiology 1975;114:647-48

37. Spackman EW. X-ray diagnosis of double perforation of the eyeball after injection of air into the space of Tenon. Am J Ophthalmol 1932;15:1007-12

38. Last MA. Contrast mediums in orbital roentgenography. Arch Ophthalmol 1938;19:1031

39. Sandera R. Pneumotenon: Uber eine neaue konbinierte kontrast darstelling des spatiom interfaciale Tenoni und der hinteren sklera. Roentgenpraxia 1930;2:175-80

40. Montresor D. Orbitografia con mezzi di contrasto. Atti Soc Oft Lomb $1952 ; 2: 258$

41. Moniz E. L'encephalographie arterielle, son importance dans la localization des tumeurs cerebrales. Rev Neurol (Paris) 1927;2:72-90

42. Lindgren E, Greitz T. The Stockholm school of neuroradiology. AJNR Am J Neuroradiol 1995; 16:351-60

43. Rosenbaum AR, Eldevik OP, Mani JR, et al. In re: Amundsen P. Cerebral angiography via the femoral artery with particular reference to cerebrovascular disease-Acta Neurol Scand 1967; suppl. 31:115. AJNR Am J Neuroradiol 2001;22:585-89

44. Ziedses Des Plantes B. Eine neue method zur differenzierung in der roentgenographile. Acta Rad 1932;13:182-91

45. Howes WE. Sectional roentgenology of the larynx. Radiology 1939;33:586-97

46. Leborgne FE. Tomtographic study of cancer of the larynx. AJR Am J Roentgenol 1940;43:493-99

47. Holvey KH, Rosenthal LM. Tomography in the region of the maxillary sinuses. Radiology 1942;42:458-65

48. Dillon WP. Head and neck imaging. AJNR Am J Neuroradiol 2000;21:25-28

49. Dublier W Jr, von Gal H, Freemond A, et al. Orbital pneumatography. 1956;66:387-92

50. Johnson DH Jr, Hunter DR. Temporal bone radiography: a screening survey approach. South Med J 1975;68:1385-87

51. Maguire GH. The larynx: simplified radiological examination using heavy filtration and high voltage. Radiology 1966;87:102-10

52. Lewis LJ. Larynx examination by spot-films. Radiology 1962;78:468-70

53. Schreiber MH. Fluoroscopic and spot-film examination of the larynx. Radiology 1962;79:969-72

54. Doust BD, Ting YM. Xeroradiography of the larynx. Radiology 1974;110: 727-30

55. Shebesta EM. Temporal bone studies. Radiology 1938;30:110-16

56. Hoeffner EG, Mukherji SK, Srinivasan A, et al. Neuroradiology back to the future: spine imaging. AJNR Am J Neuroradiol 2012;33:999-1006

57. Cormack AM. Representation of a function by its line integrals, with some radiological applications. J Appl Physics 1963;34:2722-27

58. Cormack AM. Representation of a function by its line integrals, with some radiological applications. II. J Appl Physics 1964;35:2908-13

59. Lampbert VL, Zelch JV, Cohen DN. Computed tomography of the orbits. Radiology 1974;113:351-54

60. Ledley RS, Di Chiro G, Luessenhop AJ, et al. Computer transaxial x-ray tomography of the human body: a new tomographic instrument is able to distinguish between soft tissues everywhere in the body. Science 1974;186: 207-12

61. Rothman SL, Allen WE, Simone JF. Direct coronal computerized tomography. Comput Tomogr 1977;1:157-65

62. Takahashi M, Tamakawa Y, Shindo M, et al. Computerized tomography of the paranasal sinuses and their adjacent structures. Comput Tomogr 1977;1:295-311

63. Thawley SE, Gado M, Fuller TR. Computerized tomography in the evaluation of head and neck lesions. Laryngoscope 1978;88:451-59

64. Forbes WS, Fawcitt RA, Isherwoos I, et al. Computed tomography in the diagnosis of diseases of the paranasal sinuses. Clin Radiol 1978;29:501-11

65. Shaffer KA, Haughton VM, Wilson CR. High resolution computed tomography of the temporal bone. Radiology 1980;134:409-14

66. Mancuso AA, Maceri D, Rice D, et al. CT of cervical lymph node cancer. AJR Am J Roentgenol 1981;136:381-85

67. Gatenby RA, Mulhern CB Jr, Strawitz J, et al. Comparison of clinical and computed tomographic staging of head and neck tumors. AJNR Am J Neuroradiol 1985;6:399-401

68. Gatenby RA, Mulhern CB Jr, Richter MP, et al. CT-guided biopsy for detection and staging of tumors of the head and neck. AJNR Am J Neuroradiol 1984;5:287-90

69. Babbel RW, Harnsberger HR, Sonkens J, et al. Recurring patterns of inflammatory sinonasal disease demonstrated on screening sinus CT. ANJR Am J Neuroradiol 1992;13:903-12

70. Goldman LW. Principles of CT and CT technology. J Nucl Med Technol 2007;35:115-28

71. Heiken JP, Brink JA, Vannier MW. Spiral (helical) CT. Radiology 1993;189: $647-56$ 
72. Suojanen JN, Mukherji SK, Dupuy DE, et al. Spiral CT in evaluation of head and neck lesions: work in progress. Radiology 1992;183:281-83

73. Mukherji SK, Castillo M, Huda W, et al. Comparison of dynamic and spiral CT for imaging the glottis larynx. J Comput Assist Tomogr 1995;19:899-904

74. Zima A, Carlos R, Gandhi G, et al. Can pretreatment CT perfusion predict response of advanced squamous cell carcinoma of the upper aerodigestive tract treated with induction chemotherapy? AJNR Am J Neuroradiol 2007;28:328-34

75. Schöder H, Yeung HW, Gonen M, et al. Head and neck cancer: clinical usefulness and accuracy of PET/CT image fusion. Radiology 2004;231:65-72

76. Taveras JM. Neuroradiology: past, present and future. Radiology 1990;175: 593-602

77. Lufkin R, Hanafee W. MRI of the head and neck. Magn Reson Imaging 1988;6:69-88

78. Castelijns JA, Gerritsen GJ, Kaiser MC, et al. Invasion of laryngeal cartilage by cancer: comparison of CT and MR imaging. Radiology 1987;166:199-206

79. Zoarski GH, Lufkin RB, Bradley WG J, et al. Multicenter trial of gadoteridol, a nonionic gadolinium chelate, in patients with suspected head and neck pathology. AJNR Am J Neuroradiol 1993;14:955-61

80. Tien R, Dillon WP, Jackler RK. Contrast-enhanced MR imaging of the facial nerve in 11 patients with Bell's palsy. AJNR Am J Neuroradiol 1990;11:735-41

81. Daniels DL, Czervionke LF, Pojunas KW, et al. Facial nerve enhancement in MR imaging. AJNR Am J Neuroradiol 1987;8:605-07
82. Tien RD, Dillon WP. Herpes trigeminal neuritis and rhombencephalitis on Gd-DTPA-enhanced MR imaging. AJNR Am J Neuroradiol 1990;11:413-14

83. Dietz RR, Davis WL, Harnsberger HR, et al. MR imaging and MR angiography in the evaluation of pulsatile tinnitus. AJNR Am J Neuroradiol 1994;15:879-89

84. Wippold FJ 2nd. Head and neck imaging: the role of CT and MRI. J Magn Reson Imaging 2007;25:453-65

85. Srinivasan A, Dvorak R, Perni K, et al. Differentiation of benign and malignant pathology in the head and neck using $3 \mathrm{~T}$ apparent diffusion coefficient values: early experience. AJNR Am J Neuroradiol 2008;29:40-44

86. Galbán CJ, Mukherji SK, Chenevert TL, et al. A feasibility study of parametric response map analysis of diffusion-weighted magnetic resonance imaging scans of head and neck cancer patients for providing early detection of therapeutic efficacy. Transl Oncol 2009;2:184-90

87. Cao Y, Popovtzer A, Li D, et al. Early prediction of outcome in advanced headand-neck cancer based on tumor blood volume alterations during therapy; a prospective study. Int J Radiation Oncology Biol Phys 2008;5:1287-90

88. Kim S, Loevner LA, Quon H, et al. Prediction of response to chemoradiation therapy in squamous cell carcinomas of the head and neck using dynamic contrast-enhanced MR imaging. AJNR Am J Neuroradiol 2010;31:262-68

89. Curtin HD, Ishwaran H, Mancuso AA, et al. Comparison of CT and MR imaging in staging of neck metastases. Radiology 1998;207:123-30

90. Som PM, Curtin HD, Mancuso AA. Imaging-based nodal classification of neck metastatic adenopathy. AJR Am J Roengenol 2000;174:837-44 